\title{
Resistance against Erosive Challenge of Dental Enamel Treated with 1,450-PPM Fluoride Toothpastes Containing Different Biomimetic Compounds
}

\author{
Paulo H. P. D’Alpino ${ }^{3, \odot}$ Fábio C. Sampaio ${ }^{1,4}$ \\ ${ }^{1}$ Programa de Pós-Graduação Stricto sensu em Odontologia, \\ Universidade Federal da Paraíba, PB, Brazil \\ ${ }^{2}$ Department of Morphology, Federal University of Paraíba, Centro \\ de Ciências da Saúde, Brazil \\ ${ }^{3}$ Faculdade de Ciências de Bauru, Departamento de Física, \\ Universidade Estadual Paulista, Bauru, Sao Paolo, Brazil \\ ${ }^{4}$ Departamento de Clínica e Odontologia Social, Universidade \\ Federal da Paraíba, Centro de Ciências da Saúde, Brazil
}

Nayanna L. S. Fernandes ${ }^{1}$, Juliellen L. da Cunha ${ }^{2}$ Andressa F. B. de Oliveira ${ }^{2}$

\begin{abstract}
Address for correspondence Paulo H. P. D’Alpino, Faculdade de Ciências de Bauru, Universidade Estadual Paulista, Bauru, Sao Paolo Avenue Luiz Edmundo Carrijo Coube, 14-01, Bauru, Sao Paolo CEP 17033-360, Brazil (e-mail: paulodalpino@gmail.com).
\end{abstract}

Eur J Dent 2021;15:433-439

\section{Abstract}

Keywords

- enamel

- dentin

- tooth remineralization

- toothpaste

- scanning electron microscope
Objectives This in vitro study aimed to characterize the superficial and subsurface morphology of dental enamel treated with fluoridated gels containing different biomimetic compounds after erosive challenge.

Materials and Methods Bovine incisor teeth were sectioned to obtain enamel blocks $(4 \mathrm{~mm} \times 4 \mathrm{~mm} \times 6 \mathrm{~mm} ; n=5)$ that were demineralized to create artificial caries lesions and treated by $\mathrm{pH}$ cycling interspersed with exposure to fluoridated toothpaste. During $\mathrm{pH}$ cycling (demineralization and remineralization for 2 and 22 hours, respectively) for 6 days, the enamel blocks were exposed to toothpaste slurries under agitation with one of the dental gels: Regenerate Enamel Science (NR-5 technology), Daily Regenerator Dental Clean (REFIX technology), and Sensodyne Repair \& Protect (Novamin technology). The enamel blocks were subjected to an erosive challenge, immersed in 50\% citric acid for 2 minutes, and then washed with plenty of distilled water. The surface and cross-sectional were assessed using scanning electron microscope (SEM). The elemental analyses (weight percentage) were determined with an energy-dispersive X-ray spectroscopy (EDS).

Results Enamel treated with the product containing REFIX technology presented a smoother surface morphology compared to the other treatments. The higher resistance to the erosive challenge can be attributed to a silicon-enriched mineral layer formed on the enamel induced by the REFIX-based toothpaste. This was not observed in the specimens treated with the other technology-containing toothpastes.

Conclusion The REFIX technology seemed to be the most promising compared to the Novamin and NR-5 technologies. In addition to forming a surface mineralized layer, the enamel treated with REFIX technology associated with the $\mathrm{pH}$ cycling resisted a subsequent erosive challenge. published online

May 31, 2021
DOI https://doi.org/

$10.1055 / \mathrm{s}-0041-1725576$

ISSN 1305-7456. (c) 2021. European Journal of Dentistry.

This is an open access article published by Thieme under the terms of the Creative Commons Attribution-NonDerivative-NonCommercial-License, permitting copying and reproduction so long as the original work is given appropriate credit. Contents may not be used for commercial purposes, or adapted, remixed, transformed or built upon. (https://creativecommons.org/licenses/by-nc-nd/4.0/).

Thieme Medical and Scientific Publishers Pvt. Ltd. A-12, 2nd Floor, Sector 2, Noida-201301 UP, India 


\section{Introduction}

Dental erosion, defined as an irreversible chemical wear of the dental hard tissue without the involvement of bacteria, represents a tooth pathology that causes patient discomfort. ${ }^{1}$ Enamel remineralized by natural saliva is not able to withstand the recurrent erosive attack to the tooth structure. ${ }^{2}$ Therefore, preventive measures are indicated for preventing progressive, erosive tooth wear. ${ }^{3}$ Fluoride-containing oral care products used against enamel and dentin erosion might promote remineralization through apatite crystallization or replacement of the lost mineral. ${ }^{4}$ In fact, most of these products only reduce the hydroxyapatite dissolution to some extent. ${ }^{4}$ Recently, a new generation of biomimetic oral care products, using advanced technologies with stronger surface bioactivity, has been developed to optimize the interaction with the dental tissues. ${ }^{5}$ Different components or supplements associated with fluoride were added as ingredients in these products aiming to reproduce the natural process of dental tissue mineralization ${ }^{5,6}$ and boost the remineralization and regeneration potential of the hydroxyapatite. ${ }^{7.8}$

Several promising biomimetic approaches to prevent tooth erosion have been investigated. One of the approaches comprises altering the dissolution properties of the hydroxyapatite with different foreign ions as substituents in the different sites of the hydroxyapatite molecule. ${ }^{9,10}$ Each ionic grouping of the hydroxyapatite molecule can be replaced by another of the same or different valence, either anionic or cationic. ${ }^{9,11}$ Changes in the solubility of hydroxyapatite may occur depending on the substitution at the calcium, phosphate, and/or hydroxyl sites. ${ }^{11}$ The degree of substitution by foreign ions can vary from low substitution (such as fluoride, magnesium, and potassium) to a complete substitution (three sites). ${ }^{12}$ The properties of the ion-substituted hydroxyapatite may vary according to crystallite morphology, crystallinity, particle size, and foreign ion substitute. ${ }^{9}$

A proprietary technology named REFIX was recently developed. It comprises a fluoride-containing toothpaste in association with phosphates and silica. According to the manufacturer, this association favors the formation of a fluoridated apatite and the deposition of silicon which was also incorporated deep into the hydroxyapatite and the open dentinal tubules. ${ }^{13} \mathrm{~A}$ recent in vitro study ${ }^{14}$ demonstrated that brushing teeth with the REFIX-containing toothpaste induced the formation of a silicon-enriched mineral layer on the enamel surface, proving the biomimetic mechanism of action of this fluoridated oral care product. To date, the effect of REFIX technology to prevent tooth erosive wear is unclear. This in vitro study aimed to characterize the mineral content and surface and cross-sectional morphology of enamel treated with fluoridated toothpaste containing REFIX technology after an erosive challenge.

\section{Materials and Methods}

\section{Specimen Preparation of Dental Enamel}

Enamel blocks ( $4 \mathrm{~mm} \times 4 \mathrm{~mm} \times 2 \mathrm{~mm}$ ) were prepared from extracted bovine incisor teeth and stored in $0.08 \%$ thymol solution. The specimens $(n=5)$ were embedded in self-cured acrylic resin circular molds $16-\mathrm{mm}$ diameter and $3-\mathrm{mm}$ deep. The outer enamel surface was ground flat with grit papers (600-1,500 grades) under water cooling and polished with 1- $\mu \mathrm{m}$ diamond paste (Extec Corporation, Enfield, CT) in a rotating polishing machine PSK-2V (Skill-tec Comércio e Manutenção Ltda, São Paulo, SP, Brazil).

\section{Caries-Like Lesion Formation}

Following 5-min sonication in water using an ultrasonic device, one-third of the exposed enamel surface was covered with two layers of nail varnish (Risque; Niasi, Taboão da Serra, São Paulo, Brazil) as a reference sound area. Then, the specimens were demineralized to form an artificial caries lesion. Subsurface enamel demineralization was carried out using a modified model. ${ }^{15}$ Following 5 -min sonication in water using an ultrasonic device, the enamel blocks were immersed individually in $32 \mathrm{~mL}$ of a demineralizing solution containing $1.3 \mathrm{mM} / \mathrm{L} \mathrm{Ca}\left(\mathrm{NO}_{3}\right)_{2} 4 \mathrm{H}_{2} \mathrm{O}, 0.78 \mathrm{mM} / \mathrm{L} \mathrm{NaH}_{2} \mathrm{PO} 4$ $\mathrm{H}_{2} \mathrm{O}$ in $0.05 \mathrm{M} / \mathrm{L}$ acetate buffer, $0.03 \mathrm{mgF} / \mathrm{mL}(\mathrm{NaF}), \mathrm{pH}$ of $5.0,32 \mathrm{~mL} /$ specimen, during 16 hours at $37^{\circ} \mathrm{C}$.

\section{The pH Cycling}

Before the remineralization $\mathrm{pH}$ cycling model, ${ }^{16}$ the enamel specimens had another one-third of its surface covered with two layers of nail varnish (Risque) as a reference for caries lesion area. The specimens were submitted to a $\mathrm{pH}$ cycling model at $37^{\circ} \mathrm{C}$ for 6 days. The blocks were immersed individually in a remineralization solution (1.5 mM.L-1 calcium, 0.9 mM.L-1 phosphate, $150 \mathrm{mM}$.L-1 potassium chloride in $0.02 \mathrm{mM}$.L-1 cacodylic buffer, $\mathrm{pH}=7.0 ; 0.02 \mu \mathrm{gF} / \mathrm{mL}$ and $1 \mathrm{~mL} / \mathrm{mm}^{2}$ ), for 22 hours. The cariogenic challenge was performed by immersing the enamel blocks in a demineralization solution (2.0 mM.L-1 calcium and phosphate in $75 \mathrm{mM}$.L-1 acetate buffer, $\mathrm{pH}=4.7 ; 0.03 \mu \mathrm{gF} / \mathrm{mL}$ and $3 \mathrm{~mL} / \mathrm{mm}^{2}$ ) for 2 hours per day (12-2 p.m.). Twice a day, at 10 a.m. and 2 p.m., the enamel blocks were exposed to toothpaste slurries (toothpaste: deionized water, 1:3 w/w; $2 \mathrm{~mL} /$ enamel specimen) for 1 minute, under agitation. Enamel blocks were then rinsed with deionized water between each step. Then, the enamel blocks were individually immersed in a remineralization solution at $37^{\circ} \mathrm{C}$. The de and remineralizing solutions were changed daily. Between the steps, the specimens were water rinsed with deionized water for 5 seconds. Deionized water rinses were performed between each steps. In between treatments, each enamel block was individually immersed in remineralization solution at $37^{\circ} \mathrm{C}$. The de- and remineralizing solutions were freshly changed every day. The toothpastes selected for the present study are described in - Table $\mathbf{1}$.

\section{Erosive Challenge}

After the caries pH cycling, the blocks were then subjected to an erosive challenge. Enamel blocks were immersed in 50\% citric acid for 2 minutes, and subsequently washed in abundant distilled water for at least 5 minutes. ${ }^{17}$ The results were compared to untreated control half blocks. 
Table 1 Composition of the toothpastes selected for the study

\begin{tabular}{|c|c|c|c|}
\hline Product & Ingredients & Active agents & $\begin{array}{l}\text { Lot no. } \\
\text { Expiry date }\end{array}$ \\
\hline $\begin{array}{l}\text { Regenerate Enamel } \\
\text { Science }^{\text {a }}\end{array}$ & $\begin{array}{l}\text { Glycerin, calcium silicate, PEG- } 8 \text {, hydrated silica, } \\
\text { trisodium phosphate, sodium phosphate, aqua, } \\
\text { PEG'60, sodium lauryl sulfate, aroma, flavor, synthetic } \\
\text { fluorphlogopite, sodium saccharin, polyacrylic acid, tin } \\
\text { oxide, limonene, Cl } 77891 \\
\text { pH: } 8.92 \text { (Tomaz et al) } \text { (T) }^{13}\end{array}$ & $\begin{array}{l}1,450 \text { ppm F- (as sodium } \\
\text { fluoride and sodium } \\
\text { monofluorophosphate) } \\
\text { NR-5 technology: calcium sili- } \\
\text { cate and sodium phosphate }\end{array}$ & $\begin{array}{l}\text { L72878CCApril, } \\
2020\end{array}$ \\
\hline $\begin{array}{l}\text { Regenerador } \\
+ \text { Sensitive } \\
\text { DentalClean }^{\mathrm{b}}\end{array}$ & $\begin{array}{l}\text { Glycerin, silica, sorbitol, sodium lauryl sulfate, aqua, } \\
\text { aroma, PEG-12, cellulose gum, O-phosphoric acid, } \\
\text { xylitol, sodium saccharin, triclosan, menthol, mica, } \\
\text { sodium benzoate } \\
\text { pH: } 4.73 \text { (Tomaz et al) })^{13}\end{array}$ & $\begin{array}{l}\text { 1,450 ppm F- (as sodium } \\
\text { fluoride) } \\
\text { REFIX technology } \\
\text { Tetrasodium pyrophosphate }\end{array}$ & $\begin{array}{l}41531 \\
\text { May, } 2021\end{array}$ \\
\hline $\begin{array}{l}\text { Sensodyne Repair \& } \\
\text { Protect }^{c}\end{array}$ & $\begin{array}{l}\text { Glycerin, PEG-8, hydrated silica, pentasodium triphos- } \\
\text { phate, sodium lauryl sulfate, flavor, titanium dioxide, } \\
\text { polyacrylic acid, cocamidopropyl betaine, sodium } \\
\text { saccharin. } \\
\text { pH: } 8.63 \text { (João-Souza et al) }{ }^{40}\end{array}$ & $\begin{array}{l}\text { 1,450 ppm } \mathrm{F}^{-} \text {(as sodium } \\
\text { fluoride) } \\
\text { Calcium sodium phosphosilicate } \\
5 \% \text { (Novamin) }\end{array}$ & $\begin{array}{l}\text { BN 028E } \\
\text { December, } 2019\end{array}$ \\
\hline
\end{tabular}

Abbreviations: PEG, polyethylene glycol; F-, fluoride.

aManufacturer's information: Rabbit Corp., Londrina, PR, Brazil.

'Manufacturer's information: Unilever UK Limited, Leatherhead, Surrey, United Kingdom.

'Manufacturers' information: GlaxoSmithKline, Philadelphia, Pennsylvania, United States.

\section{Characterization of the Enamel Surfaces by Scanning Electron Microscopy Imaging Observation and Energy-Dispersive X-Ray Spectroscopy}

The morphological analysis of the specimens was performed using a scanning electron microscope (SEM; TESCAN VEGA3, LMU, Kohoutovice, the Czech Republic) operating at $15 \mathrm{kV}$. The blocks were first sputter coated with gold in a vacuum evaporator (MED 010; Balzers, Balzers, Liechtenstein) and then microscopically analyzed to obtain photomicrographs of the surface morphology of the treated specimens ( $\times 1,000$ magnification). Representative images of selected regions of the specimens were obtained to characterize the morphological aspect of the surface. The energy-dispersive X-ray spectroscopy (EDS) point analysis (80 $\mathrm{mm}^{2}$, silicon drift detector [SDD], Oxford Instruments, Concord, Massachusetts, United States) was performed to determine a qualitative elemental analysis of the specimens, operating in high vacuum mode with an accelerating voltage of $15 \mathrm{kV}$. Five points per sample were randomly selected (300 $\mu^{2}$ per point), and the mean values were calculated.

\section{Characterization of the Cross-Sections by Scanning Electron Microscope Imaging Observation}

For the subsurface analysis, cross-sections of the bovine blocks were obtained by longitudinally sectioning the specimens under water cooling. Both half blocks were used for the SEM analysis. The halves were dehydrated in silica gel for 3 hours. The specimens were then gold-sputtered and evaluated using SEM.

\section{Results}

-Fig. 1 shows the representative scanning electron micrographs of the enamel surfaces treated with the different toothpastes after the $\mathrm{pH}$ cycling (images above) and after the erosive challenge (images below). After the erosive challenge, the extent to which the enamel surface presented a characteristic morphological aspect of eroded mineral tissues depended on the previous treatments (-Fig. 1B). The morphological aspect of the eroded enamel surfaces in the specimens treated with the toothpaste containing NR-5 technology (Regenerate Enamel Science) resembled the control group (-Figs. 1D and 1B , respectively). Similarly, eroded morphology was observed for the specimens treated with the product containing Novamin (Sensodyne Repair \& Protect; - Fig. 1H), which also resembled the control group. On the other hand, the specimens treated with the product containing REFIX technology presented a smoother enamel surface morphology compared to the other treatments (-Fig. 1F).

-Table 2 shows the elemental mapping of the enamel treated with the different toothpastes and after the erosive challenge. EDS detected different amounts of carbon, oxygen, silicon, phosphorus, and calcium before and after the erosive challenge. In the specimens treated with the REFIX technology, no changes in the chemical elements were observed after the erosive challenge, which agrees with the morphological analysis. Conversely, a reduction in the percentage weight of calcium was observed in the specimens treated with Novamin after the erosive challenge (from 34.11 to 29.33\%). The percentage weight of calcium increased in the eroded specimens treated with NR-5 (from 28.07 to $30.39 \%$ ). However, this increase may be not a real increase, instead the resulting of measuring the calcium content of the enamel layer exposed after the erosive challenge. This can be confirmed by the $\mathrm{Ca} / \mathrm{P}$ ratio after the erosive challenge (2.11), which is similar to that found in untreated bovine hydroxyapatite (2.08). ${ }^{18}$ The percentage weight of silicon was similar after the erosive challenge for the specimens treated with the REFIX and Novamin technologies. Conversely, when the enamel was treated with the NR-5-containing toothpaste, a decrease in the percentage weight was observed (from 0.33 to 

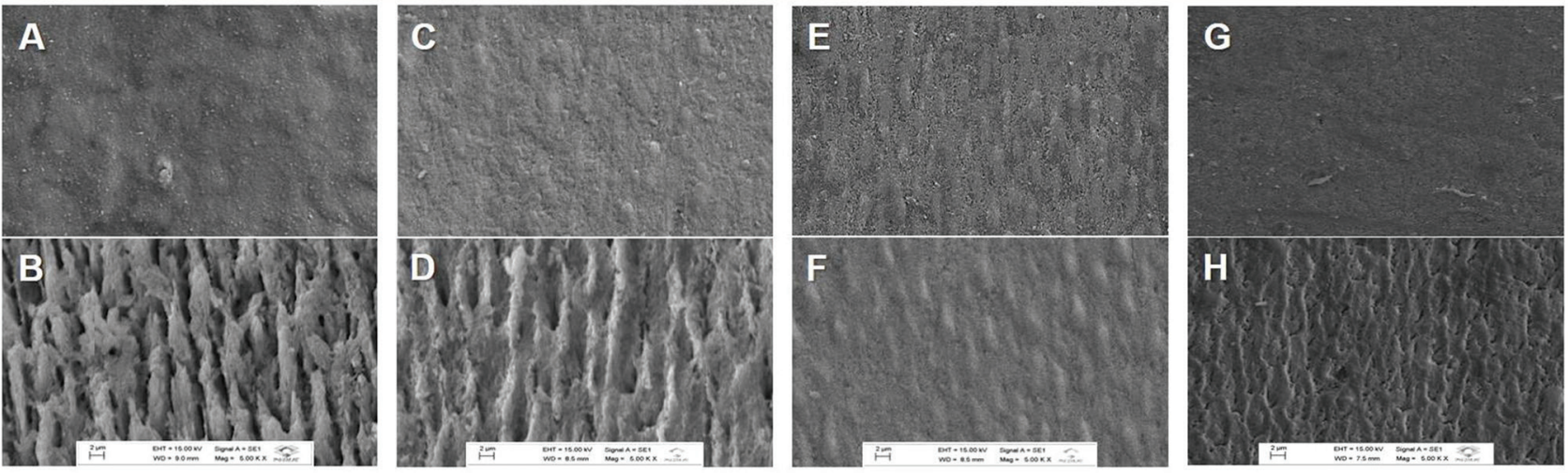

Fig. 1 A representative scanning electron micrograph of the enamel surfaces treated with the different toothpastes during the $\mathrm{pH}$ cycling (images above) and after the erosive challenge (images below). (A, B) The morphological aspect of the control (untreated area) before and after the erosive challenge of the control, untreated group; (C, D) Morphology of the enamel surface treated with toothpaste containing NR-5 technology (Regenerate Enamel Science), before and after the erosive challenge. (E, F) Representative image of the morphology of the enamel surface treated with the product containing REFIX technology before and after the erosive challenge. (G, H) Representative micrograph of the morphology of the enamel surface treated with a product containing Novamin (Sensodyne Repair \& Protect), before and after the erosive challenge. Mag, magnification. WD. Working distance. EHT: Electron high tension. HV. high vacuum. WD. Working distance. CMEUFPR. Centro de Microscopia Eletrônica da Universidade Federal do Paraná. There is no need to spell out VEGA3, TESCAN. These words are specifications of the SEM model.

Table 2 Elemental mapping of the enamel treated with the different toothpastes and after erosive challenge

\begin{tabular}{|l|l|l|l|l|l|l|l|l|l|l|l|l|l|l|l|}
\hline & \multicolumn{2}{|c|}{ C weight \% } & \multicolumn{2}{c|}{ O weight \% } & \multicolumn{2}{c|}{ Ca weight \% } & \multicolumn{2}{c|}{ P weight \% } & \multicolumn{2}{c|}{ Si weight \% } & \multicolumn{2}{c|}{ Na weight \% } & \multicolumn{2}{c|}{ Ca/P ratio } \\
\hline Toothpaste & Before & After & Before & After & Before & After & Before & After & Before & After & Before & After & Before & After \\
\hline $\begin{array}{l}\text { Regenerate } \\
\text { Enamel Science }\end{array}$ & 7.36 & 6.48 & 32.09 & 30.90 & 28.07 & 30.39 & 14.17 & 14.39 & 0.33 & 0.27 & 0.42 & 0.53 & 1.98 & 2.11 \\
\hline $\begin{array}{l}\text { Regenerador } \\
\text { Diário } \\
\text { DentalClean }\end{array}$ & 6.92 & 7.14 & 31.97 & 32.35 & 31.61 & 30.72 & 15.31 & 15.11 & 0.42 & 0.41 & 0.43 & 0.31 & 2.06 & 2.03 \\
\hline $\begin{array}{l}\text { Sensodyne } \\
\text { Repair \& } \\
\text { Protect }\end{array}$ & 4.95 & 7.60 & 18.97 & 25.14 & 34.11 & 29.33 & 16.74 & 14.27 & 0.32 & 0.33 & 0.29 & 0.36 & 2.03 & 2.05 \\
\hline
\end{tabular}

Abbreviations: C, carbon; Ca, calcium; Na, sodium; O, oxygen; P, phosphorus; Si, silicon.

$0.27 \%$ weight). The highest percentage weight of silicon was found in the specimens treated with REFIX technology, before and after the erosive challenge ( 0.42 and $0.41 \%$, respectively).

-Fig. 2 shows micrographs of cross-sectional areas of the enamel treated with the different toothpastes. A mineralized layer formed on the enamel surface after treatment with NR-5 (-Fig. 2A) and REFIX technologies (-Fig. 2B). A thicker mineral layer was observed for REFIX in all the specimens evaluated. Conversely, no mineralized surface layer was observed in the specimens treated with Novamin technology (-Fig. 2C). This toothpaste is known to induce the formation of a mineralized layer on the dentin and inside the dentinal tubules. ${ }^{19}$

-Fig. 3 shows micrographs of cross-sectional areas of the enamel treated with REFIX technology, in which a mineralized layer formed on the enamel surface is observed ( $\mathbf{- F i g}$. 3B), in comparison with the untreated enamel (-Fig. 3A). The product containing REFIX technology induced the formation of a mineralized layer when associated with $\mathrm{pH}$ cycling. This layer was approximately $6-\mu \mathrm{m}$ thick (-Fig. 3B).

-Fig. 4 shows photomicrographs of the morphology of cross-sectional areas of the enamel treated with the REFIX-containing toothpaste comparing the effect of the erosive challenge with an intact, untreated enamel area. The eroded area was around $15-\mu \mathrm{m}$ deep in the intact enamel (-Fig. 4A). Conversely, in the specimens treated with the REFIX technology, virtually no erosion was observed and the mineralized layer after the erosion challenge (-Fig. 4B).

\section{Discussion}

As dental erosion may lead to irreversible loss of hydroxyapatite, it is of paramount importance to prescribe products with remineralizing potential that can assist in the mineral gain of the demineralized surface and reduce the solubility of the dental structure in recurrent acidic challenges. ${ }^{9}$ As previously pointed out, fluoride-containing products may have antierosive properties, but they are only able to repair smaller enamel lesions. ${ }^{20,21}$ Promising biomimetic approaches to erosion prevention have been developed., ${ }^{4,22}$

The toothpaste with the proprietary technology called NR-5 contains, according to the manufacturer, sodium phosphate associated with calcium silicate. Also, according to the manufacturer, this technology was developed by combining calcium silicate, sodium phosphate salts, and fluoride. This technology was proposed to accelerate the mineralization 

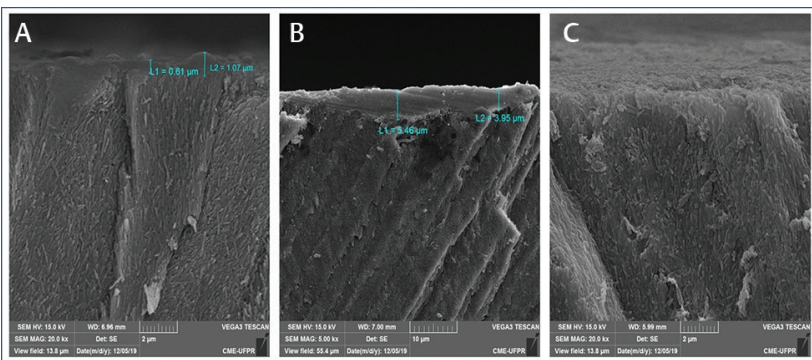

Fig. 2 Representative scanning electron micrographs of the enamel cross sections of the enamel treated with the different technology-containing fluoride toothpastes. (A) NR-5 technology (Regenerate Enamel Science); (B) REFIX technology (Regenerador + Sensitive DentalClean); (C) Novamin technology (Sensodyne Repair \& Protect). MAG, magnification; SEM, scanning electron microscopes.

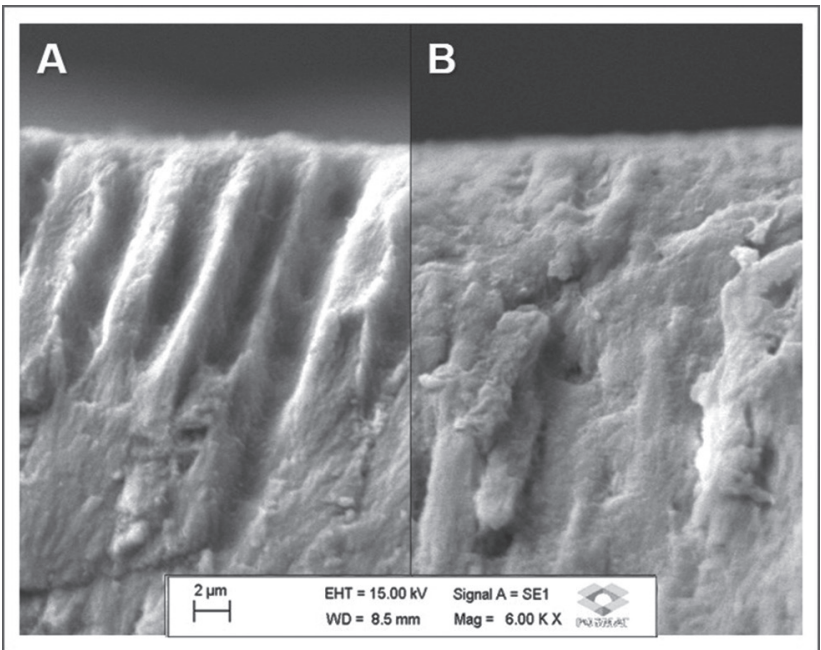

Fig. 4 Scanning electron micrographs of the morphological analysis of the cross-sectional areas of the enamel comparing the untreated control area (A) and the treated area (B) with the REFIX-containing fluoride toothpaste. Mag, magnification. WD. Working distance. EHT: Electron high tension.

processes provided by saliva, assisting the nucleation of hydroxyapatite and in the formation of minerals in the enamel, thereby remineralizing, protecting, and repairing the enamel. A previous in vitro study ${ }^{23}$ investigated the repair and protective properties after the deposition of calcium silicate on acid-eroded enamel surfaces. That study demonstrated that calcium silicate could transform into hydroxyapatite and be deposited on both intact and eroded enamel surfaces, providing significant protection against erosive challenges. This technology seems to induce the formation of a mineralized layer on the enamel surface after treatment with NR-5, as demonstrated in the present study ( $\mathbf{- F i g}$. $\mathbf{2 A}$ ). In another in vitro study ${ }^{13}$ the toothpaste with NR-5 technology favored the recovery of superficial enamel hardness more than $100 \%$ compared to the untreated control. Conversely, this effect was not observed at the enamel subsurface, demonstrating that this technology was less effective at remineralizing the enamel in depth. This helps to explain the reasons for not promoting an effective protection against the erosive challenge.

The other product containing Novamin technology (Sensodyne Repair \& Protect) uses sodium and calcium

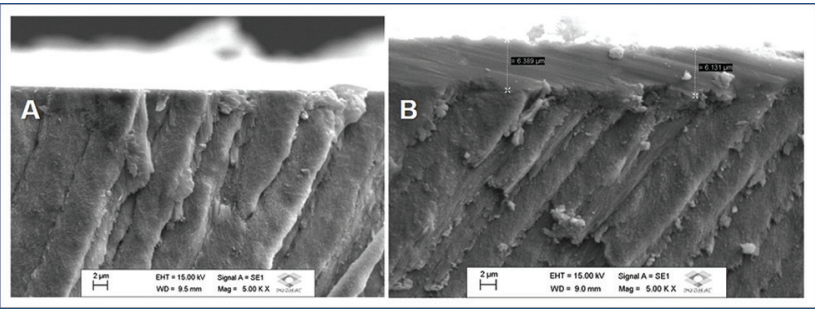

Fig. 3 (A, B) Scanning electron micrographs of the morphological analysis of the cross-sectional areas of the enamel showing the formation of a mineralized surface layer after treatment with the REFIX-containing fluoride toothpaste (B), in comparison to the untreated specimen (A). Mag, magnification; WD, Working distance; EHT, Electron high tension.

phosphosilicate (Bioglass) in the form of an amorphous inorganic compound. ${ }^{24}$ According to the manufacturer, a series of chemical reactions occurs when Bioglass is in contact with an aqueous solution, leading to the formation of a layer of carbonated hydroxyapatite on the dentin that forms an insoluble mineralized layer on the surface. This technology may favor another mechanism of action in enamel, possibly altering the structure of the enamel hydroxyapatite, and reinforcing it without actually forming a superficial mineralized layer on the enamel. In the present study, it was not observed the formation of a mineralized layer on the enamel surface ( - Fig. 2C), although the formation of a less-soluble surface hydroxyapatite, which is resistant to acid challenges, may occur. ${ }^{25}$

In an in vitro study, ${ }^{26}$ the protective effect of four commercial toothpastes containing antierosion agents was investigated. The authors found that the toothpaste containing Novamin was not effective in preventing the erosion effect caused by orange juice when applied either before or after the erosive challenge. The authors of a recent systematic review ${ }^{27}$ searched for clinical evidence of the effectiveness of Novamin in publications, evaluating its action as a remineralizing agent. The analysis of the different studies led to the conclusion that Novamin had significantly less clinical evidence to demonstrate its effectiveness as a remineralization agent in treating both carious and noncarious lesions. The authors recommended better-designed clinical trials to make definitive recommendations about this technology. ${ }^{27}$

The toothpaste containing proprietary REFIX technology, according to the manufacturer, represents a novel, multifunctional, phosphate-based dental gel technology in an acidified stabilized phosphate/fluoride complex which is established especially in saliva. ${ }^{13}$ The combination of toothpaste, saliva, and dental tooth structures favors the generation of new minerals containing calcium/phosphate/fluorine, promoting the enamel surface, and remineralizing within the subsurface carious lesion. ${ }^{13}$ This product presents an acid $\mathrm{pH}$ that may be the main reason for its effectiveness due to the formation of calcium phosphate crystals in an acidic environment. ${ }^{13,28}$

In the present study, it was demonstrated that a mineralized layer was formed on the enamel surface after treatment with REFIX technology ( - Figs. 2B and 3B), in comparison with the untreated enamel $(-$ Fig. $\mathbf{3 A}$ ). A previous study demonstrated the formation of a silicon-enriched mineral 
layer on the enamel surface induced by the REFIX-based toothpaste was favored by the formation of complexes of the bioactive particles of calcium, phosphorus, and sodium. ${ }^{14}$ Substituting $\mathrm{PO}_{4}$ with $\mathrm{SiO}_{4}$ is believed to affect the mechanical properties of the silicon-enriched hydroxyapatite in a dose-dependent manner, decreasing hardness and the elastic modulus. ${ }^{29}$ Conversely, the silicon content in the toothpaste formulation in association with fluorine and phosphate groups induces increased bioactivity and apatite-forming ability of hydroxyapatite, which is enhanced by the substitution of silicon, or silicate, into the remineralizing hydroxyapatite. ${ }^{30,31}$ In this manner, a protective effect is provided by inducing the formation of hydroxyapatite after its deposition onto the eroded surfaces. ${ }^{23}$

The results of the present study can also be explained by the $\mathrm{pH}$ at which the remineralization processes occur (-Table $\mathbf{1}$ ). The biomimetic effect of the technology-containing fluoride toothpastes may induce the nucleation and growth of new enamel crystals by incorporation into the porous spaces of the lesion, and at later stages by means of the growth and fusion with the preexisting crystals. In this manner, a faster remineralization process may be expected when treating the enamel with these multifunctional toothpastes compared with conventional fluoride toothpastes. Fluorine ions, known to reduce hydroxyapatite solubility, can replace hydroxyl ions. ${ }^{32}$ The small-sized fluoride anions are able to diffuse throughout the enamel matrix in either acidic or basic $\mathrm{pH}$, inducing the remineralization process using a nucleophilic attack on silicon, coordinating to it, and promoting subsequent reactions. ${ }^{33}$ In an acidic $\mathrm{pH}$, such as the REFIX-containing toothpaste, the remineralization process in the presence of silicon leads to the formation of a less porous hydroxyapatite structure $(<2 \mathrm{~nm}) \cdot{ }^{34}$ In addition, the REFIX product contains $30 \%$ more silicon than the other products (-Table 2). Conversely, in a basic medium, such as the NR-5and Novamin-containing toothpastes, there is a tendency to form a mesoporous enamel structure, ${ }^{34}$ with porosity varying from 2 to $50 \mathrm{~nm} .{ }^{35,36}$ This also helps to explain the differences in the resistance to the erosive challenge after treatment among the technology-containing fluoride toothpastes.

\section{Limitations}

Considering the limitations of the present in vitro study, the protocol used to evaluate the protective effectiveness of the selected fluoride toothpastes can be explained considering that both cariogenic and erosive challenges might simultaneously occur in the oral cavity, depending on different etiological factors. ${ }^{37,38}$ By treating the enamel with the fluoride toothpastes allowed changes in the hydroxyapatite structure, which ends up forming fluoridated apatite and the deposition and/or replacement of hydroxyapatite sites with other substitutes. This also seems to occur deeper into the hydroxyapatite. ${ }^{39}$ Without this protocol, it would not be possible to evaluate the effectiveness of the toothpastes to promote a protective effect after exposure to the erosive challenges. This protective effect of the toothpastes containing different technologies may not only be restricted to the enamel surface but also to the enamel subsurface. It is true that the erosive challenge used in the present study has also limitations, but it is a valid and well-established method..$^{17}$ Another limitation relies on the fact that this morphologic evaluation is qualitative, and one may argue that the results are quite subjective. In spite of this fact, the images are clear to demonstrate the results when the treatments were compared.

The present study found that the protective effect against the erosive challenge was material dependent. The toothpaste containing 1,450 ppm of sodium fluoride with REFIX technology enabled the formation of a mineralized surface layer less affected by the erosive challenge. This outcome appears to be due to the formation of an acid-resistance silicon-enriched mineral surface layer on the enamel surface. Although the treatment with the toothpaste containing NR-5 technology also enabled the formation of a mineralized surface layer, an eroded enamel surface morphology was observed after the erosive challenge, similar to the untreated enamel control. Conversely, no mineralized surface layer was observed in the specimens treated with the toothpaste containing Novamin technology, and the enamel surface morphology was significantly affected by the erosive challenge.

\section{Conclusion}

The present study characterized the enamel surface and subsurface morphologies of specimens treated with different 1,450-ppm fluoride toothpastes containing different biomimetic technologies. These technologies were developed to accelerate the remineralization process or to minimize the demineralization process of dental tissues, especially in the event of repetitive erosive challenges. Despite the limitations of the present in vitro study, the preferred REFIX technology was the most promising compared to other Novamin and NR-5 technologies. In addition to forming a mineralized layer superficially on the enamel, the most important result was the ability to resist acid dissolution by the erosive challenge. Further studies are needed to investigate the performance of the dental gel containing the REFIX technology using in situ and in vivo studies on the effectiveness of the dental gel on dental substrates.

\section{Conflict of Interest}

None declared.

\section{References}

1 Lussi A. Erosive tooth wear - a multifactorial condition of growing concern and increasing knowledge. Monogr Oral Sci 2006;20:1-8

2 Lopes RM, da Silva JSA, João-Souza SH, et al. Enamel surface loss after erosive and abrasive cycling with different periods of immersion in human saliva. Arch Oral Biol 2020;109:104549

3 Ganss C, Klimek J, Brune V, Schürmann A. Effects of two fluoridation measures on erosion progression in human enamel and dentine in situ. Caries Res 2004;38(6):561-566 
4 Roveri N, Battistella E, Bianchi CL, et al. Surface enamel remineralization: Biomimetic apatite nanocrystals and fluoride ions different effects. J Nanomater 2009;20099. Article ID 746383

5 Xiao Z, Que K, Wang H, et al. Rapid biomimetic remineralization of the demineralized enamel surface using nano-particles of amorphous calcium phosphate guided by chimaeric peptides. Dent Mater 2017;33(11):1217-1228

6 Elgamily H, Safwat E, Soliman Z, Salama H, El-Sayed H, Anwar M. Antibacterial and remineralization efficacy of casein phosphopeptide, glycomacropeptide nanocomplex, and probiotics in experimental toothpastes: an in vitro comparative study. Eur J Dent 2019;13(3):391-398

7 Cardoso CdeA, Lacerda B, Mangueira DF, et al. Mechanisms of action of fluoridated acidic liquid dentifrices against dental caries. Arch Oral Biol 2015;60(1):23-28

8 Kraivaphan P, Amornchat C. Comparative clinical efficacy of three toothpastes in the control of supragingival calculus formation. Eur J Dent 2017;11(1):94-98

9 Enax J, Epple M. Synthetic hydroxyapatite as a biomimetic oral care agent. Oral Health Prev Dent 2018;16(1):7-19

10 Vallet-Regí M, Arcos D. Silicon substituted hydroxyapatites. A method to upgrade calcium phosphate based implants. J Mater Chem 2005;15:1509-1516

11 Palard M, Champion E, Foucaud S. Synthesis of silicated hydroxyapatite Ca10(PO4)6-x(SiO4)x(OH)2-x. J Sol State Chemistry 2008;181:1950-1960

12 Dunlop JWC, Fratzl P. Biological composites. Annu Rev Mater Res 2010;40:1-24

13 Tomaz PLS, Sousa LA, Aguiar KF, et al. Effects of 1450-ppm fluoride-containing toothpastes associated with boosters on the enamel remineralization and surface roughness after cariogenic challenge. Eur J Dent 2020;14(1):161-170

14 Vilhena FV, de Oliveira SML, Matochek MHM, Tomaz PLS, Oliveira TS, D'Alpino PHP. Biomimetic mechanism of action of fluoridated toothpaste containing proprietary REFIX technology on the remineralization and repair of demineralized dental tissues: an in vitro study. Eur J Dent 2021;15(2):236-241 doi:10.1055/s-0040-1716781

15 Queiroz CS, Hara AT, Paes Leme AF, Cury JA. pH-cycling models to evaluate the effect of low fluoride dentifrice on enamel deand remineralization. Braz Dent J 2008;19(1):21-27

16 Vieira AE, Delbem AC, Sassaki KT, Rodrigues E, Cury JA, Cunha RF. Fluoride dose response in pH-cycling models using bovine enamel. Caries Res 2005;39(6):514-520

17 Raafat Abdelaziz R, Mosallam RS, Yousry MM. Tubular occlusion of simulated hypersensitive dentin by the combined use of ozone and desensitizing agents. Acta Odontol Scand 2011;69(6):395-400

18 Falla-Sotelo FO, Rizzutto MA, Tabacniks MH, et al. Analysis and discussion of trace elements in teeth of different animal species. Braz J Phys 2005;35:761-762

19 Rajesh KS, Hedge S, Arun Kumar MS, Shetty DG. Evaluation of the efficacy of a $5 \%$ calcium sodium phosphosilicate (Novamin) containing dentifrice for the relief of dentinal hypersensitivity: a clinical study. Indian J Dent Res 2012;23(3):363-367

20 Gjorgievska ES, Nicholson JW, Slipper IJ, Stevanovic MM. Remineralization of demineralized enamel by toothpastes: a scanning electron microscopy, energy dispersive X-ray analysis, and three-dimensional stereo-micrographic study. Microsc Microanal 2013;19(3):587-595

21 Lelli M, Putignano A, Marchetti M, et al. Remineralization and repair of enamel surface by biomimetic Zn-carbonate hydroxyapatite containing toothpaste: a comparative in vivostudy. Front Physiol 2014;5:333

22 Philip N. State of the art enamel remineralization systems: the next frontier in caries management. Caries Res 2019;53(3):284-295
23 Parker AS, Patel AN, Al Botros R, et al. Measurement of the efficacy of calcium silicate for the protection and repair of dental enamel. J Dent 2014;42(Suppl 1):S21-S29. Doi:10.1016/ S0300-5712(14)50004-8

24 Joshi S, Gowda AS, Joshi C. Comparative evaluation of NovaMin desensitizer and Gluma desensitizer on dentinal tubule occlusion: a scanning electron microscopic study. J Periodontal Implant Sci 2013;43(6):269-275

25 Burwell AK, Litkowski LJ, Greenspan DC. Calcium sodium phosphosilicate (NovaMin): remineralization potential. Adv Dent Res 2009;21(1):35-39

26 Wang X, Megert B, Hellwig E, Neuhaus KW, Lussi A. Preventing erosion with novel agents. J Dent 2011;39(2):163-170

27 Khijmatgar S, Reddy U, John S, Badavannavar AN, D Souza T. Is there evidence for Novamin application in remineralization?: a systematic review. J Oral Biol Craniofac Res 2020;10(2):87-92

28 Vilhena FV, Polassi MR, Paloco EAC, Alonso RC, Guiraldo RD, D'Alpino PH. Effectiveness of toothpaste containing REFIX technology against dentin hypersensitivity: a randomized clinical study. J Contemp Dent Pract 2020;21(6):609-614

29 Surmeneva MA, Mukhametkaliyev TM, Tyurin AI, et al. Effect of silicate doping on the structure and mechanical properties of thin nanostructured RF magnetron sputter-deposited hydroxyapatite films. Surf Coat Tech 2015;275:176-184

30 Gibson IR, Huang J, Best SM, Bonfield W, Eds. Enhanced in vitro cell activity and surface apatite layer formation on novel silicon-substituted hydroxyapatites. 12th International Symposium on Ceramics in Medicine; 1999; Nam, Japan: World Scientific Publishing Co. Pte. Ltd.

31 Carrouel F, Viennot S, Ottolenghi L, Gaillard C, Bourgeois D. Nanoparticles as anti-microbial, anti-inflammatory, and remineralizing agents in oral care cosmetics: a review of the current situation. Nanomaterials (Basel) 2020;10(1):1-32

32 Yao F, LeGeros JP, LeGeros RZ. Simultaneous incorporation of carbonate and fluoride in synthetic apatites: effect on crystallographic and physico-chemical properties. Acta Biomater 2009;5(6):2169-2177

33 Pavan FA, Gobbi SA, Moro CC, Costa TMH, Benvenutti EV. The influence of the amount of fluoride catalyst on the morphological properties of the anilinepropylsilica xerogel prepared in basic medium. J Porous Mater 2002;9:307-311

34 Gorrepati EA, Wongthahan P, Raha S, Fogler HS. Silica precipitation in acidic solutions: mechanism, pH effect, and salt effect. Langmuir 2010;26(13):10467-10474

35 Ariga K, Vinu A, Hill JP, Mori T. Coordination chemistry and supramolecular chemistry in mesoporous nanospace. Coord Chem Rev 2007;251:2562-2591

36 Sing KSW. Adsorption methods for the characterization of porous materials. Adv Colloid Interface Sci 1998;76-77:3-11

37 Tschammler C, Simon A, Brockmann K, Röbl M, Wiegand A. Erosive tooth wear and caries experience in children and adolescents with obesity. J Dent 2019;83:77-86

38 Alaraudanjoki V, Laitala ML, Tjäderhane L, Pesonen P, Lussi A, Anttonen V. Association of erosive tooth wear and dental caries in Northern Finland Birth Cohort 1966 - an epidemiological cross-sectional study. BMC Oral Health 2016;17(1):6

39 Amaechi BT, AbdulAzees PA, Alshareif DO, et al. Comparative efficacy of a hydroxyapatite and a fluoride toothpaste for prevention and remineralization of dental caries in children. BDJ Open 2019;5:18

40 João-Souza SH, Lussi A, Baumann T, Scaramucci T, Aranha ACC, Carvalho TS. Chemical and physical factors of desensitizing and/or anti-erosive toothpastes associated with lower erosive tooth wear. Sci Rep 2017;7(1):17909. Doi:10.1038/ s41598-017-18154-8 